Wilma González ${ }^{1}$, Pablo I. Altieri ${ }^{1,2 *}$, Héctor Banchs ${ }^{1,2}$, Diego Iravedra ${ }^{1}$, Rafael Calderón ${ }^{2}$, Iván GonzálezCancel $^{2}$, Carmen Gurrea ${ }^{2}$, Nelson Escobales $^{1}$ and Maria Crespo ${ }^{1}$

${ }^{1}$ Department of Medicine and Physiology, University of Puerto Rico, Medical Sciences Campus, Pablo I. Altieri

${ }^{2}$ Cardiovascular Center of Puerto Rico and the Caribbean, Pablo I. Altieri

Dates: Received: 02 July, 2014; Accepted: 18 September, 2014; Published: 20 September, 2014

*Corresponding author: Pablo I. Altieri, MD, Box 8387, Humacao, Puerto Rico 00792, Tel: (787) 6307638; Fax: (787) 725-6423; E-mail: altierip@prtc.net

www.peertechz.com

Keywords: Metabolic syndrome; Heart transplant; HDL; Rejection

\section{Research Article \\ HDL as a Biomarker of Rejection in Heart Transplant}

\begin{abstract}
Abbreviations
BMI: Body Mass Index; dBP: Diastolic Blood Pressure; FBS: Fasting Blood Sugar; HDL: High Density Lipoprotein; HT: Heart Transplant; LDL: Low Density Lipoprotein; MetS: Metabolic Syndrome; sBP: Systolic Blood Pressure; HDL-C= High Density Lipopoprotein Cholesterol; BP: Blood Pressure; T2D: Type 2 Diabetes; apoCIII: Apolipoprotein C-III; Lp-PLA2: Lipoprotein associated phospholipase A2; p38-MAPK: Inhibitor of Mitogen Activated Protein Kinase; SAA: Serum Amyloid A; SA-A1: Serum Amyloid A-1; MCP-1= Monocyte Chemoattractant Protein-1; Ox$\mathrm{PL}=$ Oxidized Phospholipids; $\mathrm{PON} 1=$ Paraxonase $1 ; \mathrm{SD}=$ Standard Deviation
\end{abstract}

\section{Introduction and Background}

The incidence of metabolic syndrome (MetS) is growing each year; approximately one third of the population suffers from MetS [1]. MetSis an important issue to study because it emerges as a novel risk in cardiovascular disease events due to endothelial dysfunctions, diabetes mellitus, hypertension and dyslipidemia [2].

MetS is a risk factor related with cardiovascular diseases, insulin resistance, post-transplantation complications, and late morbidity and mortality [3,4]. MetS is described as by a clustering of cardiovascular risk factors that are correlated with pathophysiological defects that are indicative of metabolic burden associated with disturbances in adipose tissue, including diabetes, obesity, dyslipidemia and hypertension [3,5]. MetS is defined according to ethnicity/race, specific waist circumference and the presence of two of the following: [6]

a. triglycerides: $>150 \mathrm{mg} / \mathrm{dl}$ 
b. high density lipoprotein- cholesterol (HDL-C): $<40 \mathrm{mg} / \mathrm{dl}$ for males

c. HDL-C: $<50 \mathrm{mg} / \mathrm{dl}$ for females

d. blood pressure: $>130 / 85 \mathrm{mmHg}$

e. fasting blood sugar: $>100 \mathrm{mg} / \mathrm{dl}$

The prevalence of MetS has been strongly associated with obesity due to its fundamental control of the distribution of free fatty acids disorders including dyslipidemia and insulin resistance preceding type 2 diabetes [6]. Visceral adipose tissue is highly susceptible to catecholamine-induced lipolysis compared to subcutaneous tissue [7]. This visceral fat produced in patients with MetS is related to insulin sensibility, which moderates angiogenic proteins, metabolic regulators and inflammatory mediators that produced hypertension, inflammation, endothelial dysfunction and the production of atheromas [2,5]. Heart transplant patients tend to develop MetS while also presenting with dysfunctional levels of high density lipoproteincholesterol [8]. This manuscript describes the changes in our population (Table 1) that lead to MetS and the consequences of MetS. Moreover, the importance of functional and dysfunctional HDL will be discussed, because changes in both are extremely important for the survival of transplanted patients (Table 2). Also, the importance of a marked and persistent elevation of HDL can be used as a biomarker of an impending rejection process (Figure 1). The HDL-C of $70 \mathrm{mg}$ / $\mathrm{dl}$ was not chosen as a cut-off, it was the mean value of the evaluation of HDL-C in the rejected patients who died. This will lead to an aggressive change in the rejection protocol to avoid this disaster. This last observation is the main point, we want to stress in this paperHDL levels as a biomarker in heart transplant pathophysiology.

\section{Material and Methods}

The records of 101 heart transplant patients were reviewed in the Cardiovascular Center of Puerto Rico and the Caribbean, to determine the incidence of Met Sin the transplant population and the body mass index (BMI), systolic blood pressure, diastolic blood pressure, fasting blood sugar, total cholesterol, low density lipoprotein (LDL), high density lipoprotein (HDL), triglycerides and drugs in the congestive heart failure patients before and after heart transplantation, were monitored. Seven autopsies specimens of rejected hearts were evaluated, and emphasis was given to the amount of atherosclerosis in the coronary arteries and aorta. The data were examined with Student's t-test with p-values, and the levels are expressed as the mean values \pm SD's. The autopsies were performed according to a standard protocol. Emphasis was given to the transplanted heart including the aorta and coronary arteries.

We evaluated 101 patients whose mean age was 51 years. Sixty patients were males and 41 were females. Nineteen deaths were due to rejection; $81.0 \%$ of the deaths were females and $19.0 \%$ were males. Only seven autopsies were performed; autopsies were not performed on all the deceased patients because some of the relatives objected. The age of the transplanted hearts were 21 years, and all hearts were from healthy patients without any metabolic or lipid abnormalities.

\section{Results}

One hundred one patients with heart transplant were studied.

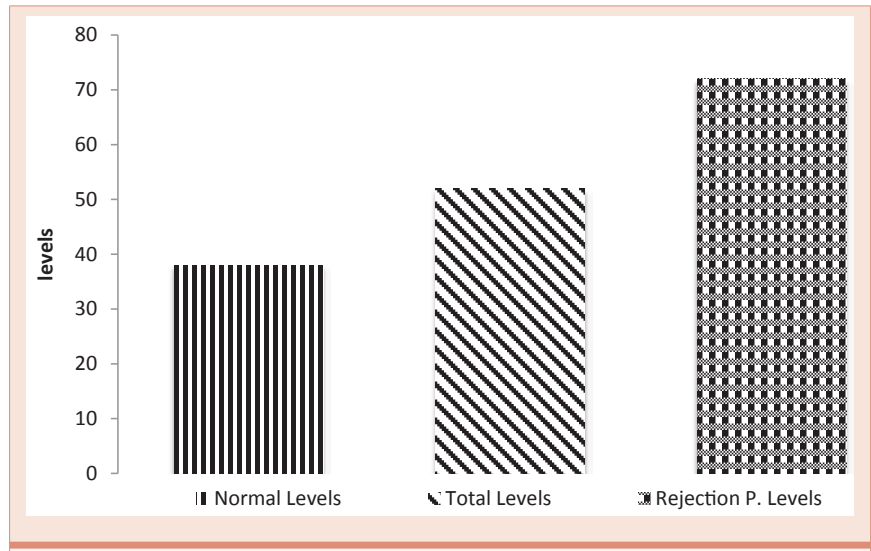

Figure 1: HDL-C Results compared to normal controls (mg/dl). HDL: High Density Lipoprotein Cholesterol; P: Patients

Sixty-five patients were males and 36 were female. The mean age was 51 years (Table 1). The observed pre- and post-transplant metabolic changes were as follows (Table 2):
1. BMI: $25 \pm 4-28 \pm \mathrm{Kg} / \mathrm{m}^{2}(\mathrm{P}<0.05)$.
2. sBP: $107 \pm 13-131 \pm 20 \mathrm{mmHg}(\mathrm{P}<0.05)$.
3. dBP: $70 \pm 13-81 \pm 10 \mathrm{mmHg}$. $(\mathrm{P}<0.05)$.
4. FBS: $107 \pm 37-117 \pm 55 \mathrm{mg} \%(<0.164)$.
5. Total cholesterol: $170 \pm 55-189 \pm 32 \mathrm{mg} / \mathrm{dl}(\mathrm{P}<0.05)$.
6. Total HDL: $38 \pm 16-52 \pm 17 \mathrm{mg} / \mathrm{dl}(\mathrm{P}<0.05)$.
7. Total LDL: $99 \pm 20-83 \pm 15 \mathrm{mg} / \mathrm{dl}(<0.34)$.
8. Triglycerides: $163 \pm 10-188 \pm 12 \mathrm{mg} / \mathrm{dl}(<0.144)$.

Our data shows that all of the patients developed Mets. The HDL of the entire group increased from $38 \mathrm{mg} / \mathrm{dl}$ to $52 \mathrm{mg} / \mathrm{dl}$ (Figure 1). These changes cannot be solely attributed to the immunosuppressive treatment. Nineteen of the patients died due to rejection. The HDL's of patients who exhibited rejection increased from $47 \pm 22$ to $71 \pm$ $40 \mathrm{mg} / \mathrm{dl}(\mathrm{P}<.005)$. This increase persisted through the course of the rejection period (Figure 1).

The mean age of the transplanted hearts was 21 years; $81 \%$ of the donors were females and $19 \%$ were male. The rejections occurred inless than five years ( 3.5 years). Only seven autopsies were performed. Four of the autopsies revealed severe atherosclerotic changes in the coronary arteries and aorta, and these findings are likely attributable to dysfunctional HDL. The LDL levels were reduced post transplant. Due to this LDL was not considered to be a factor in this aggressive atherosclerotic process.

\section{Discussion}

MetS represents a common interaction between genetic tendencies, metabolic factors, nutrition, physical activities, and environmental factors that affect allograft patients [9]. MetS is accompanied by risk factors that are associated with cardiovascular disease, primarily, ischemic heart disease, which is an important predictor of post-transplantation complications $[3,10]$. Several studies 
Table 1: Sample Data.

\begin{tabular}{|c|c|}
\hline Patients & $\mathrm{N}=101$ \\
\hline Males & 60 \\
\hline Females & 41 \\
\hline Mean Age & $51 \pm 3$ years \\
\hline Deaths due rejection & 16 \\
\hline Males & $19.0 \%$ \\
\hline Females & $81.0 \%$ \\
\hline
\end{tabular}

Table 2: Results.

\begin{tabular}{|l|c|c|c|}
\hline & Pre HT* & Post HT* & P-Value \& Significance \\
\hline${ }^{1} \mathrm{BMI}\left(\mathrm{kg} / \mathrm{m}^{2}\right)$ & $24 \pm 4$ & $28 \pm 5$ & $<.05$ \\
\hline${ }^{2} \mathrm{SBP}(\mathrm{mmHg})$ & $107 \pm 17$ & $131 \pm 20$ & $<.05$ \\
\hline${ }^{3} \mathrm{dBP}(\mathrm{mmHg})$ & $70 \pm 13$ & $81 \pm 10$ & $<.05$ \\
\hline${ }^{4} \mathrm{FBS}(\mathrm{mg} \%)$ & $107 \pm 37$ & $117 \pm 55$ & 0.164 \\
\hline Total cholesterol (mg/dl) & $170 \pm 55$ & $189 \pm 32$ & $<.05$ \\
\hline${ }^{5} \mathrm{HDL}(\mathrm{mg} / \mathrm{dl})$ & $38 \pm 16$ & $52 \pm 17$ & $<.05$ \\
\hline${ }^{6} \mathrm{LDL}(\mathrm{mg} / \mathrm{dl})$ & $99 \pm 20$ & $83 \pm 15$ & 0.34 \\
\hline Triglycerides (mg/dl) & $163 \pm 10$ & $188 \pm 12$ & 0.144 \\
\hline
\end{tabular}

${ }^{1}$ BMI: Body Mass Index; ${ }^{2}$ Systolic BP: Systolic Blood Pressure; ${ }^{3}$ Diastolic BP Diastolic Blood Pressure; ${ }^{4} \mathrm{FBS}$ : Fasting Blood Sugar; ${ }^{5} \mathrm{HDL}$ : High Density Lipoprotein; ${ }^{6} \mathrm{LDL}$ : Low Density Lipoprotein; ${ }^{*} \mathrm{HT}$ : Heart Transplant

have shown that insulin resistance and visceral obesity are main factors in MetS, which causes post-transplantation abnormalities between muscles and adipose tissue in patients who tend to be obese, or overweight or develop abdominal obesity $[5,10]$.

In patients with type 2 diabetes and MetS, there are predispositions for elevation of Angiotensin II and endothelin I due to the activation of the neuro-hormonal system by systemic inflammation. These elevations results in inflammatory cytokines, endothelin I and smooth muscle proliferation, which initiates the atherosclerotic process $[9,10]$. The incidence of atherosclerosis in MetS is related to pathogenesis of insulin resistance, which tends to produce abnormalities in fat storage. The accumulation of triglycerides by visceral fat provokes a reduction in energy intake reduction and free fatty acids release, which discharge cytokines, fatty tissue and inflammatory cells that affects adipokines and increase the risk factors for cadiovascular disease [11]. Visceral adiposity has been associated with excess of free fatty acids release and suppression, increased hyper triglyceridemia and the production of alterations in HDL-C levels [11]. Doubts regarding HDL functionality have been proposed and correlated with the post-transplantation incidence. Higher levels have been associated with reduction in cardiovascular disease risk factors, but recent studies and drugs effects suggest that an elevation is not necessarily beneficial [12]. We propose that a marked elevation of HLD-C to levels of around $70 \mathrm{mg} / \mathrm{dl}$ is a warning that a severe chronic rejection process is active. We think that those changes can be used as a biomarker of a severe rejection process.

HDL particle compositions are critical to biological maintenance and functionality. This functionality has been strongly suggested to be better indicators that levels that assess cardio-protection. To maintain body homeostasis, this functionality tempers endothelial function and cholesterol efflux function, regulates pro-inflammatory and promigratory factors, oxidation and prevents thrombotic activity related to platelets [13]. Conversely, the disfunctionallity has been associated with certain genetic variants, and this association is corroborated by some drug results that have demonstrate opposite, inflammatory, thrombotic, oxidative and cholesterol influxincreasing results.

HDL is composed principally of apolipoprotein A-1 (apoA1) and apolipoprotein A-2 (apoA2), and interaction with ABCA1 gene expression regulates efflux capacity via reverse cholesterol transport. Mutations in this pathway are associated with greater incidence of atherosclerotic burden [13-15,19]. Although higher levels had been suggested to diminish cardiovascular disease risk, we proposed abnormal levels affect influx and efflux activity. The aforementioned finding supports our results of higher levels of HDL post-transplantation, particularly in the rejected hearts and severe atherosclerotic activity upon the autopsies.

The pathophysiologies of cardiovascular diseases are influenced by apoptotic endothelial activities, which are controlled by HDL function. However, anti-apoptotic effects vary according to the dysfunctional activity $[13,20]$. Disruptions of endothelial monolayer can lead to apoptotic pathways and enhance cardiovascular disease risk factors. Cell death has been associated with intracellular $\mathrm{Ca}^{2+}$, which is caused by oxidized LDL and reversed by HDL particle functions [13]. Moreover, growth factors and deprivation-related apoptosis are related. The association with lysophospholipid sphingosylphorycholine inhibits apoptotic pathways by signaling, and, nitric oxide synthase is as a paracrine mediator in dietary fats that induces insuline resistance $[11,13,20,21]$. In contrast to these findings, some authors have proposed that chronic and inflammatory diseases reduce the atheroprotective functions of HDL, which is strongly associated with the acute phase due to loss of function in reverse cholesterol transport [12,17,20-22].

The relation between HDL elevation and protein response strong during the acute phase and leads to pathological consequences [22]. Recent studies have proposed differences in HDL protein cargos [22] and have suggested that not all particles are equal. Abnormal levels of HDL proteins in the acute phase have been reported. Reduced clusterin levels and elevations in apolipoprotein-CIII (apoCIII) elevation, serum amyloid A-1 (SA-A1) and lipoprotein-associated phospholipase A2 (Lp-PLA2) are biomarkers due to their vascular endothelial cell contribution to inflammation and atherogenesis [18,20,23-24]. Probably a marked and persistent elevation of HDL can be proposed as a biomarker or rejection.

Riwanto et al. [20] proposed that higher levels of clusterin are related to the mechanism of HDL in apoptotic pathways that are mediated by phoinostide 3-kinase/Akt (PI3/Akt) functioning in healthy subjects and that this mechanism is not activated in coronary artery disease subjects. The BCL2 class of proteins are crucial mediators of apoptosis, and HDL modulates the BCLXL protein via PI3K/Akt activation $[25,27]$. In contrast, lower levels of clusterin protein lead toproapoptotic effects that are specific to HDL and not the serum by activating tBid $[20,26]$ and, induce apoptosis related to the release of 
cytochrome c in mitocilin-deficient mitochondria [27]. Furthermore, Riwanto [20] demonstrated that the inhibition of mitogen-activated protein kinase (p38-MAPK) phosphorylation increases tBid expression by blocking apoCIII. Relations between apoCIII and cardiovascular disease risk factors, MetS and T2D patients have been proposed based on findings that reduction in plasma apoCIII are paralleled by elevated plasma triglycerides [28]. The acute phase of inflammation is accompanied by elevated levels of serum amyloid A(SAA) family proteins, which are principal non-invasive biomarker of allograft rejection due to their G-protein receptor-mediated pro inflammatory and atherosclerotic activities $[29,30]$. Töle et al. [30] recently demonstrated that the cardio-protective properties of HDL are lost during inflammatory diseases with high triglyceride levels in end stage renal disease patients. The recruitment of monocytes in the subendothelium is preceded by monocyte chemo attractant protein-1 (MCP-1), which leads to an increased incidence of atherosclerotic activity. Töle [30] found that the capacity of HDL is reduced by the inhibition of MCP-1 production in end stage renal disease patients, and that this process is related to higher levels of protein fraction that are highly enriched with SAA protein. These authors also proposed that MCP-1 with the formyl-peptide receptor 2 is produced; similar proposals have been made in other studies that have found produced effluxes of HDL activity in end stage renal disease patients, especially whose with diabetes Type 2 [18].

In the present study, we reviewed the different factors related to cardiovascular disease that contribute to MetS in heart transplant patients. We presented a trend suggesting that BMI is related to the predisposition for being obese or to the development of posttransplantation obesity, which is correlated with higher levels of cholesterol and strongly related to moderate to severe atherosclerotic activity on autopsy. Due to the resistance of donor patients to autopsies after heart transplant, we performed seven autopsies that exhibited this atherosclerotic activity. These finding are likely due to post-transplantation HDL dysfunctionality. We proposed a dysfunctional activity that involves structure, function and density that will reverse the efflux activity of cholesterol to create an influx activity into the heart cells. This observation has been supported and proposed in other studies and has been related to the use of HDL protein cargos, such as apoA1, apoCIII, clusterin, SA-AI and LpPla2, as potential biomarkers of cardiovascular disease. Thus, HDL capacity in the endothelial activity plays the important role for those patients after heart transplantation. The disruption of HDL proteins and enzymes might lead to changes in the injury process by altering or inhibiting the inflammatory response that is related to helper $\mathrm{T}$ cell responses through the degradation of the endothelial functions [15-17]. We don't think LDL is a factor because there was a reduction instead of an elevation.

The development of MetS following heart transplant might be related to the permanent use of prednisone and the implications of that use rather than the immune system overreacting to a chronic rejection process by elevating HDL levels. Future research should be performed in this group of patients to determine the reasons for this phenomenon and to review the protocol to avoid further damage to the allograft.
Atherosclerotic activity stimulates monocyte adhesion, and these monocytes differentiate into macrophages and oxidized LDL, which produced foam cells that are involved in the inflammatory process. Cytokine production, reactive oxygen species and monocytes are related in the inflammatory process [17-19]. Changes in oxidative activities and proinflammatory gene expression occur due to activating platelets, monocytes adhesion and plaque formation [31].

Ostadal et al. [32] proposed that the abnormal levels related to Lp-PLA2 worsening cardiovascular events, especially in acute coronary syndrome patients, and can thus be used as biomarkers. A higher incidence of oxidative platelest (Ox-PL) than Lp-PLA2 in the artery walls leads to proinflammatory activity that produces bioactive lipid mediators that are chemo attractants for monocytes that impair endothelial function and the plasma membrane by inducing apoptotic pathways [31]. Navab et al. [17] proposed that normal HDL levels are related to $\mathrm{Ox}-\mathrm{Pl}$. In this proposed relation, the HDL-associated enzyme paraoxonase 1 (PON1), which inhibits the endothelial cell responses to $\mathrm{Ox}-\mathrm{Pl}$ and apolipoprotein $\mathrm{m}$, increased the anti-oxidative properties of HDL. Decreased levels of PON1 result in higher levels of lipid hydroperoxide in the HDL while reducing HDL-C and increasing the molecular weight of apoA1. Navab [17] proposed that a greater molecular weight in the HDL content of apoAl antibodies that recognize $\mathrm{Ox}-\mathrm{Pl}$ is a form of genetic control over the anti atherogenic properties of HDL.

The HDL levels observe in the patients that died due to rejection are related to disfunctionallity. The disruption of the endothelium leads to altered homeostasis and increases the risk of thrombosis, which places the arterial walls at risk [13]. The vascular injury activates the platelets during the acute phase, which results in greater atherosclerotic activity and triggers coagulation and platelet-rich thrombi [33].

Increased incidence of chronic rejection has been evaluated and related to metabolic disorders in patients with insulin resistance. These disorders include pathophysiological factors, such as oxidative stress, nitric oxide bioavailability, growth factors and abnormal cell signaling [22]. Dysfunctional HDL elevation in chronic rejection is related to severe atherosclerotic activity and has been linked to with glycosphingolipids in recent studies due to is modulation of the immune system and T-lymphocyte differentiation [34]. Atherosclerotic activity is produced through foam cell formation; these cells mature by accumulating inflammatory $\mathrm{T}$ cell subsets that are activated and produce chemokines, cytokines and growth factors by degrading the subendothelium, which influences the atherosclerotic lesion and protein response [35]. These findings explain the possible relationship between proteins concentrations in the HDL and atherosclerotic activity in the acute phase due to T cell subtype imbalances. The importance of this higher HDL-C level in the rejected group should be studied further and find out which sub factors of HDL is the one elevated and why, to alter the rejection protocol and avoid this fatal process. Studies with proteonics are planned to try to clarify which particle of HDL is responsible for its dysfunctionality. This marked elevation of HDL in the rejected heart, starting at the beginning of the procedure suggests that this elevation may be used as a biomarker of rejection. Also this abnormal 
statistically significant $(\mathrm{P}<0.05)$ elevation of $\mathrm{HDL}$ up to levels of 70 $\mathrm{mg} / \mathrm{dl}$, probably is due to a dysfuntional HDL which produces severe deposition of lipids in the aorta and coronaries, producing early death of the patients. Further studies should be done in HDL structure to find which particle of HDL is responsible for this abnormality of being transformed to a dysfunctional HDL and in this way being used as a biomarker.

\section{Conclusions}

Importantly, among the seven autopsies that were performed, five patients exhibited severe atherosclerotic changes. The mean age of the transplanted hearts was only 21 years. As observed, the HDL of the patients who exhibited rejection averaged $71 \pm 40 \mathrm{mg} / \mathrm{dl}$, while that of the patients who did not, averaged $47 \pm 22 \mathrm{mg} / \mathrm{dl}$ (Figure 1). We believe these finding are due to increases in dysfunctional HDL. Moreover, we propose that this significant increase in HDL can be used as a biomarker of rejection. These findings serve as a warning that changes to the immune suppression protocol should be done to try to revert the rejection process.

\section{References}

1. Johnson RJ, Stenvinkel P, Martin SL, Jani A, Sánchez-Lozada LG, et al (2013) Redefining metabolic syndrome as a fat storage condition based on studies of comparative physiology. Obesity (Silver Spring) 21: 659-664.

2. Sánchez-Lázaro IJ, Sánchez-Gómez JM, Almenar-Bonet L, Martínez-Dolz L, Muño-Giner B, et al. (2011) Long-Term prognostic implications of metabolic syndrome in heart transplant recipients. Transplant Proc 43: 2257-2259.

3. Pagadala M, Dasarathy S, Eghtesad B, McCullough AJ (2009) Posttransplant metabolic syndrome: an epidemic waiting to happen. Liver Transpl 15: 1662 1670.

4. Watt KD, Charlton MR (2010) Metabolic syndrome and liver transplantation: a review and guide to management. J Hepatol 53: 199-206.

5. Duvnjak L, Duvnjak M (2009) The metabolic syndrome- an ongoing story. J Physiol Pharmacol Suppl 7: 19-24.

6. Alberti KG, Eckel RH, Grundy SM, Zimmet PZ, Cleeman JI, et al. (2009) Harmonizing the metabolic syndrome: a joint interim statement of the International Diabetes Federation Task Force on Epidemiology and Prevention; National Heart, Lung, and Blood Institute; American Heart Association; World Heart Federation; International Atherosclerosis Society; and International Association for the Study of Obesity. Circulation 120: 16401645.

7. Arner P (1999) Catecholamine-induced lipolysis in obesity. Int J Obes Relat Metab Disord Suppl 1: 10-13.

8. Hansel B, Giral P, Nobecourt E, Chantepie S, Bruckert E, et al. Metabolic syndrome is associated with elevated oxidative stress and dysfunctional dense high-density lipoprotein particles displaying impaired antioxidative activity. J Clin Endocrinol Metab 2004; 89: 4963-4971.

9. Altieri PI, Marcial JM, Escobales N, Crespo M, Banchs H (2012) Insuline Resistance: The Metabolic Syndrome in Hispanics- The Role of Insulin Resistance and Inflammation. In: Arora S. Insulin resistance. Rijeka, Croatia: Intech Publisher 75-86.

10. Cordero Fort A, Gavira JJ, Alegría-Barrero E, Castaño S, Martín A, et al. (2006) Prevalence of metabolic syndrome in heart transplant patients: role of previous cardiopathy and years since the procedure-the TRACA study. J Heart Lung Transplant 25: 1192-1198.

11. Ebbert JO, Jensen MD (2013) Fat depots, free fatty acids, and dyslipidemia Nutrients 5: 498-508.

12. Heinecke, JW (2013) HDL's protein cargo: Friends or Foe in Cardioprotection? Circulation 127: 868-869.
13. Mineo C, Shaul PW (2012) Novel biological functions of high-density lipoprotein cholesterol. Circ Res 111: 1079-1090.

14. Fisher EA, Feig JE, Hewing B, Hazen SL, Smith JD (2012) High-density lipoprotein function, dysfunction, and reverse cholesterol transport. Arterioscler Thromb Vasc Biol 32: 2813-2820.

15. Kennedy MA, Barrera GC, Nakamura K, Baldán A, Tarr P, Fishbein MC, et al. (2005) ABCG1 has a critical role in mediating cholesterol efflux to HDL and preventing cellular accumulation. Cell Metab 1: 121-131.

16. Favari E, Ronda N, Adorni MP, Zimetti F, Salvi P, et al. (2013) ABCA1dependent serum cholesterol efflux capacity inversely correlates with pulse wave velocity in healthy subjects. J Lipid Res 54: 238-243.

17. Navab M, Reddy ST, Van Lenten BJ, Buga GM, Hough G, et al. (2012) High-density lipoprotein and $4 \mathrm{~F}$ peptide reduce systemic inflammation by modulating intestinal oxidized lipid metabolism: novel hypotheses and review of literature. Arterioscler Thromb Vasc Biol 32: 2553-2560.

18. Yamamoto S, Yancey PG, Ikizler TA, Jerome WG, Kaseda R, et al. (2012) Dysfunctional high-density lipoprotein in patients on chronic hemodialysis. J Am Coll Cardiol 60: 2372-2379.

19. Bochem AE, van Wijk DF, Holleboom AG, Duivenvoorden $R$, Motazacker $\mathrm{MM}$, et al. (2013) ABCA1 mutation carriers with low high-density lipoprotein cholesterol are characterized by a larger atherosclerotic burden. Eur Heart J 34: 286-291.

20. Riwanto M, Rohrer L, Roschitzki B, Besler C, Mocharla P, et al. (2013) Altered activation of endothelial anti- and proapoptotic pathways by highdensity lipoprotein from patients with coronary artery disease: role of highdensity lipoprotein-proteome remodeling. Circulation 127: 891-904.

21. Sessa WC (2012) A new approach to weight loss: just active endothelial NO synthase! Circ Res 111: 1111-1112.

22. Zheng C, Aikawa M (2012) High-density lipoproteins: from function to therapy. J Am Coll Cardiol 60: 2380-2383.

23. Zheng C, Azcutia V, Aikawa E, Figueiredo JL, Croce K, et al. (2013) Statins suppress apolipoprotein CIII-induced vascular endothelial cell activation and monocyte adhesion. Eur Heart J 34: 615-624.

24. Ishida K, Cucchiara B (2013) Therapeutic Options to Reduce Lp-PLA2 Levels and the Potential Impact on Vascular Risk Reduction. Curr Treat Options Cardiovasc Med 12: 313-321.

25. Guerrero AD, Welschhans RL, Chen M, Wang J (2013) Cleavage of antiapoptotic Bcl-2 family members after TCR stimulation contributes to the decision between T cell activation and apoptosis. J Immunol 190: 168-173.

26. Yin XM (2000) Signal transduction mediated by Bid, a prodeath Bcl-2 family proteins, connects the death receptor and mitochondria apoptosis pathways. Cell Res 10: 161-167.

27. Yang RF, Zhao GW, Liang ST, Zhang Y, Sun LH, et al. (2012) Mitofilin regulates cytochrome $\mathrm{c}$ release during apoptosis by controlling mitochondrial cristae remodeling. Biochem Biophys Res Commun 428: 93-98.

28. Graham MJ1, Lee RG, Bell TA ${ }^{3 r d}$, Fu W, Mullick AE, et al. (2013) Antisense oligonucleotide inhibition of Apolipoprotein C-III reduces plasma triglycerides in rodents, nonhuman primates, and humans. Circ Res 112: 1479-1490.

29. Malle E, De Beer FC (1996) Human serum amyloid A (SAA) protein: a prominent acute-phase reactant for clinical practice. Eur J Clin Invest 26: 427-435.

30. Tölle M, Huang T, Schuchardt M, Jankowski V, Prüfer N, et al. (2012) Highdensity lipoprotein loses its anti-inflammatory capacity by accumulation of proinflammatory-serum amyloid A.Cardiovasc Res 94: 154-162.

31. Leibundgut G, Arai K, Orsoni A, Yin H, Scipione C, et al. (2012) Oxidized phospholipids are present on plasminogen, affect fibrinolysis, and increase following acute myocardial infarction. J Am Coll Cardiol 59: 1426-1437.

32. Ostadal P, Vondrakova D, Kruger A, Janotka M, Psotova H, et al. (2012) Alteration in lipoprotein-associated phospholipase A2 levels during acute 
coronary syndrome and its relationship to standard biomarkers. Lipids Health Dis 11: 153.

33. Habets KL, Huizinga TW, Toes RE (2013) Platelets and autoimmunity. Eur J Clin Invest 43: 746-757.

34. Norata GD, Pirillo A, Ammirati E, Catapano AL (2012) Emerging role of high density lipoproteins as a player in the immune system. Atherosclerosis 220 11-21.

35. Haraba R, Antohe F (2011) T cells are active participants in the progression of atherosclerotic plaques. Dig J Nanomater Bios 6: 1529-1534 